Short Communication

\title{
Aggregation of MAO Coatings and Crack Formation in the Microgrooves on an Aluminum Surface
}

\author{
Manxi Sun ${ }^{1}$, Hongjian Huang ${ }^{1,}$ *,Xiaowei Wei ${ }^{2}$, Jianhui Qiu ${ }^{1}$ \\ ${ }^{1}$ Department of Machine Intelligence and Systems Engineering, Faculty of Systems Engineering, \\ Akita Prefectural University, Akita 015-0055, Japan \\ ${ }^{2}$ School of Materials Science and Engineering, Xihua University, Chengdu 610039, PR China \\ *E-mail: hongjianhuang1021@yeah.net
}

doi: $10.20964 / 2020.01 .70$

Received: 4 September 2019 / Accepted: 1 Novevember 2019 / Published: 30 November 2019

Surface microgroove pretreatment has been proven to be an effective method to increase the formation efficiency and performance of microarc oxidation (MAO) coatings. Here, the effect of the microgroove dimensions on an MAO coating was investigated systematically. The results indicate that as the opening angles of the microgrooves decrease, the coating aggregation increases and the defects become very obvious. Conversely, microgrooves that are too large lose their effect on the coating. Moreover, the MAO coatings in the central region of the microgrooves are mainly composed of a nodular structure contrasting to the volcanic structure of the planar regions.

Keywords: Micro-arc oxidation; Microgrooves; Microstructure; Defects.

\section{$\underline{\text { FULL TEXT }}$}

(C) 2020 The Authors. Published by ESG (www.electrochemsci.org). This article is an open access article distributed under the terms and conditions of the Creative Commons Attribution license (http://creativecommons.org/licenses/by/4.0/). 